\title{
USGS Microanalytical Reference Materials (MRMs) Development
}

\author{
Stephen Wilson ${ }^{1}$
}

1. Mineral Resources Program, United States Geological Survey, Denver, CO, USA.

As the use of microanalysis in geochemical studies continues to expand the need for reliable matrix matched reference materials increases. In support of internal studies the USGS reference materials project devotes considerable resources to the development of microanalytical reference materials (MRMs) which assist investigators in quantifying trace and major elements in a variety of matrices. Discussions will focus on two categories of USGS MRMs and the lessons learned in their development. The original USGS focus was on the development of homogeneous glasses using natural geologic materials. Due to oven heating limitations $\left(1350^{\circ} \mathrm{C}\right)$ materials were selected for glass preparation that contained $\leq 55 \% \mathrm{SiO}_{2}$. Melting/mixing/cooling protocols were developed in early studies using USGS basalt materials BCR-2, BHVO-2 and BIR-1. Preparation of all glass materials is accomplished by melting powdered material at $1350^{\circ} \mathrm{C}$ in a $1 \mathrm{~L}$ heavy walled platinum bowl for several hours, mixing the contents by hand using a platinum stir rod, heating for an additional two hours and then rapidly quenching the melt in deionized water. Glass materials produced in this manner (table 1) are remarkably similar in chemical composition to the starting material and have element homogeneity appropriate for EPMA and LA-ICP-MS analysis. In addition to the use of domestic geologic materials the USGS has also collaborated with international organizations to developed glass materials using their material which further expands the range of sample types. To meet the need for instrument calibration the USGS has developed a series of synthetic basalts (Synbasalts) using a combination of a manufactured glass and reagent grade chemicals. The starting glass powder (GSE-1) was designed by the USGS and prepared by Corning Glass Works in 1969. The glass was powdered and used to monitor spectrochemical mobile laboratories in use at the time. GSE-1 is the starting material of choice because it contained $500 \mathrm{ppm}$ of 46 trace elements[1,2] and was available in sufficient quantities to produce both GSE-1G (400 ppm) and serial dilutions of GSD-1G (40 ppm) and GSC-1G (4 ppm). Because the original GSE-1 material contained $\geq 62 \% \mathrm{SiO} 2$ the matrix was modified to match a BCR-2 composition through the addition of $\mathrm{Al}_{2} \mathrm{O}_{3}, \mathrm{Fe}_{2} \mathrm{O}_{3}, \mathrm{MgO}, \mathrm{CaO}, \mathrm{TiO}_{2}$, and $\mathrm{NaH}_{2} \mathrm{PO}_{4}$. The GS series of materials was prepared as described above producing approximately $600 \mathrm{~kg}$ of each glass standard.

The second area of MRM development was designed to support those low temperature studies that required the presence standard trace elements and potentially volatile elements such as $\mathrm{Hg}, \mathrm{Te}, \mathrm{Tl}, \mathrm{As}$, $\mathrm{Se}$, and Os. To meet this complex need the USGS developed a coprecipitation process which can customize the sample matrix contain trace elements that mimics natural abundances. In this process a target matrix composition is identified and soluble cation and anion solutions are prepared. Trace element aliquots are obtained from commercially available 1000 or $10,000 \mathrm{ppm}$ spectroscopic solutions and mixed in a third container. In the preparation step the cation (ex. $\mathrm{Ca}\left(\mathrm{NO}_{3}\right)_{2}$ ) and anion (ex. $\mathrm{Na}_{2} \mathrm{CO}_{3}$ ) solutions are combined along with all the individual trace element aliquots. The resulting precipitate $\left(\right.$ ex. $\left.\mathrm{CaCO}_{3}\right)$ is rapidly stirred until the contents are visually homogeneous. After settling overnight the solid phase is collected and repetitively wash/centrifuged until the supernatant conductivity is $\leq 200 \mu \mathrm{S}$ (micro Siemens). The solid material is then micronized, dried at $110 \mathrm{C}$, briefly ground in an agate shatter box and then pressed into pellets at 10,000 psi. A list of materials prepared in this manner is presented in table 1. 
Due to difference in physical properties (compression) of the produced materials two pellet preparation options are utilized depending on the integrity of the pressed pellet. Materials that compress uniformly and maintain their shape during pellet extraction from the $13 \mathrm{~mm}$ die (ex. MASS-1) are distributed as individual pellets. Materials that tend to delaminate during pellet extraction are pressed into plastic rings (13 $\mathrm{mm} \mathrm{ID}, 19 \mathrm{~mm}$ OD). The rings may be fitted with a paper backing to increase pellet stability.

MRM materials prepared in this manner undergo a preliminary homogeneity assessment at the USGS using both EPMA and LA-ICP-MS. Randomly selected fragments or pellets of each new material are analyzed at multiple locations to identify any systematic heterogeneity in the material. If the material is considered homogeneous, aliquots of glass $(<2 \mathrm{~mm}$, ground) or powder are submitted to multiple laboratories for traditional total element analysis using a variety of methods. MRMs produced by the USGS are commonly used in the microanalytical proficiency testing program known as G-probe. This program organized by the International Association of Geoanalysts (IAG) and coordinated through the USGS distributes samples to participants to evaluate laboratory accuracy. In addition to providing laboratory performance information results are compiled by the USGS and used in the certification process for MRMs.

References:

[1] AT Meyers, RG Havens and WW Niles, Developments in Applied Spectroscopy, Mid-America Spectroscopy Symposium, 20 ${ }^{\text {th }}$ Ann., (1969) Selected papers: Plenum Press, 8 (1970), p. 132.

[2] AT Meyers et al, U.S. Geological Survey Professional Paper 1013 (1976), p. 24

\begin{tabular}{|l|l|l|l|}
\hline \multicolumn{1}{|c|}{ MRM } & \multicolumn{1}{|c|}{ Matrix } & \multicolumn{1}{|c|}{ Type } & \multicolumn{1}{c|}{ Application } \\
\hline BCR-2G, BHVO-2G, BIR-1G & Basalt & glass & igneous rocks \\
AGV-2G & Andesite & glass & igneous rocks \\
DNC-1G & Dolerite & glass & igneous rocks \\
GSM-1G & Gabbro & glass & igneous rocks \\
NKT-1G & Nephelinite & glass & igneous rocks \\
W-2G & Diabase & glass & igneous rocks \\
BSWIR-1G & Basalt & glass & MORB (Indian Ocean) \\
BRP-1G & Basalt & glass & igneous rocks (Brazil) \\
JGB-1g & Gabbro & glass & igneous rocks (Japan) \\
OU-7G & Gabbro & glass & igneous rocks (UK) \\
GSC-1G $(2 G)$ & SynBasalt & glass & calibration (4 ppm) \\
GSD-1G $(2 G)$ & SynBasalt & glass & calibration (40 ppm) \\
GSE-1G $(2 G)$ & SynBasalt & glass & calibration (400 ppm) \\
MACS-3 & Carbonate & pressed powder & Coral \\
MASS-1 & Sulfide & pressed powder & FeCuZnS \\
MAPS-4 & Apatite & pressed powder & Bone (Prehistoric) \\
FeMnOx-1 & Oxide & pressed powder & FeMnOxides \\
FeAlOx-1 & Oxide & pressed powder & Alunite \\
MAOS-3 & Organic & epoxy pellet & Black Coral \\
\hline
\end{tabular}

Table 1. USGS MRM reference materials. 